\title{
Autologous Dendritic Cell Transplantation as an Adjuvant Treatment in Pleomorphic Lung Carcinoma
}

\author{
Francisco S. Chung Jr., ${ }^{1,2}$ Nelia S. Tan-Liu, ${ }^{1,3}$ Guia Imelda Elena R. Ladrera, ${ }^{1}$ Ramoncito S. Habaluyas, ${ }^{1}$ \\ Ernesto DJ. Yuson, ${ }^{1}$ Joselito J. Danguilan, ${ }^{1}$ Samuel D. Bernal, ${ }^{4}$ Juanito A. Rubio ${ }^{1}$ and Maria Teresa A. Barzaga ${ }^{1,5}$ \\ ${ }^{1}$ Molecular Diagnostics and Cellular Therapeutics Lab, Department of Pathology, Lung Center of the Philippines \\ ${ }^{2}$ Department of Biochemistry and Molecular Biology, College of Medicine, University of the Philippines Manila \\ ${ }^{3}$ Department of Pathology, College of Medicine, University of the Philippines Manila \\ ${ }^{4}$ Globetek Science Foundation, Makati City \\ ${ }^{5}$ Department of Microbiology, De La Salle Health Sciences Institute, Dasmariñas City, Cavite
}

\begin{abstract}
We embarked on autologous dendritic cells (DC) transplantation as an adjuvant therapy with chemotherapy in a pleomorphic lung carcinoma patient. DC were isolated from PBMC and primed with the autologous tumor lysate. No adverse event was noted in DC transplantation. DC administration also correlated with immunomodulation, as evidenced by an approximately 5fold increase in serum interferon gamma after 2 months. The utility of autologous DC transplantation may offer a clinical benefit with virtually no adverse event.
\end{abstract}

Key Words: autologous tumor priming, Dendritic Cell (DC), Interferon gamma

\section{Introduction}

Pleomorphic lung carcinoma is characterized by carcinomatous and sarcomatoid cells. ${ }^{1}$ This type of lung carcinoma is uncommon and few studies are reported in the literature. For this reason, its clinical management and therapeutic regimen remain inadequate. The study evaluated the potential of dendritic cells (DC) primed with autologous tumor to treat pleomorphic lung carcinoma as an adjuvant therapy with chemotherapy. Modulation of the immune response is determined after DC administration.

DC are the most effective antigen presenting cells and are considered as the sentinel of the immune system. Most cancer vaccines require cross presentation of the administered antigen by DC. After DC are activated, they migrate to the lymphoid tissues wherein T cells and B cells will be primed to reinforce the adaptive immune system. ${ }^{2}$ This is the principle that is applied by Dendreon, a US Pharmaceutical company to treat prostate cancer patients. Dendreon's Provenge ${ }^{\mathrm{TM}}$ is the first FDA-approved autologous cellular immunotherapy. ${ }^{3}$ The same scientific basis was used by the late Dr. Ralph Steinman, who won the

Corresponding author: Francisco S. Chung Jr., PhD

Molecular Diagnostics and Cellular Therapeutics Lab

Department of Pathology

Lung Center of the Philippines

Quezon Avenue, Quezon City 1104 Philippines

TeleFax: +632 9246101 local 386

Cellular Therapeutics Center

Makati Medical Center

Tower 2, Level 6, \#2 Amorsolo St. Makati City

Email: fchung@upm.edu.ph
2011 Nobel Prize for Physiology and Medicine, to treat himself for pancreatic cancer.

To date, there are several studies wherein DC are evaluated in lung cancer patients. For example, Hirschowitz and co-workers ${ }^{4}$ demonstrated the safety and tolerability of the autologous DC transplantation. Introgen's INGN-225, a p53-modified adenovirus-transduced dendritic cell vaccine is now undergoing phase 2 studies. ${ }^{5}$ In another report, ${ }^{6}$ two groups of 42 NSCLC patients were compared. The group that received chemotherapy plus DC demonstrated higher 2year overall survival rate than the group that received chemotherapy alone $(94.7+/-3.6 \%$ versus $78.8+/-7.0 \%, \mathrm{P}<$ $0.05)$. However, there was no significant difference in twoyear disease-free survival between the two groups. Interestingly, the report demonstrated that clinical outcomes are independent of measured immunologic responses. ${ }^{6}$ The various immunological markers used in the study were IFNgamma, TNF-alpha and TNF-beta. While the previous reports demonstrated the potential clinical utility of DC, this communication aims to use DC to induce tumor-specific effector $\mathrm{T}$ cells that may reduce the tumor mass and induce immunological memory to prevent tumor relapse. ${ }^{7}$

\section{Case Presentation}

\section{Leukapheresis}

An informed consent was obtained from a 38-year-old nonsmoker male patient. The study was institutionally approved by the Technical and Ethics Review Board of the Lung Center of the Philippines, following the guidelines set by World Medical Association Declaration of Helsinki. ${ }^{8}$ The subject did not have existing medical conditions severe enough to affect compliance with the protocol. Briefly, DC was mobilized using GCSF. The "buffy coat" was then obtained after 18 cycles from the apheresis machine (Haemonetics $^{\mathrm{TM}}$ ), yielding $4.65 \times 10^{9}$ cells (based on WBC count). The "buffy coat" was further separated by differential centrifugation using Lymphoprep ${ }^{\mathrm{TM}}$ to concentrate DC from peripheral blood mononuclear cells (PBMCs). 


\section{Culture of tumor}

A surgical procedure was carried out in order to harvest tumor cells. The histologically confirmed tumor specimen was processed immediately from the operating room at the Lung Center of the Philippines. Microscopic examination revealed a poorly differentiated epithelial tumor composed of several cells that are polygonal with hyperchromatic to vesicular, highly pleomorphic nuclei and ample cytoplasm disposed in dyshesive nests and surrounded by malignant spindle cells at stage 1B. Cytokeratin (DAKO) immunohistochemical studies showed diffuse and strong positive staining on all tumor cells, while vimentin test (DAKO) ruled out a sarcoma. The tumor cells were aseptically cut with scalpel blades and minced. The cells were washed three times with sterile PBS. The cells were cultured in RPMI-1640 (Invitrogen) with 10\% autologous serum plus penicillin and streptomycin (Invitrogen).

\section{Preparation of tumor lysate}

Tumor cells underwent freeze-and-thaw cycle at least 4 times. Tumor cells were irradiated with gamma rays (Gamma cell 1000) at 10,000 rads for 30 mins. The viability of the cells was confirmed using trypan blue dye exclusion. All tumor cells were nonviable. Sterility tests using thioglycollate medium revealed that the tumor lysate was free from bacterial contamination.

\section{Maturation and Priming of DC}

DC were cultured in RPMI-1640 with $10 \%$ autologous serum plus growth factors. Photomicrography (Olympus IX51 inverted microscope) from day 0 to day 7 was carried out to describe morphological changes in DC maturation. Cell surface expression of CD86 was analyzed by flow cytometry (BD FACScalibur equipped with a $488 \mathrm{~nm}$, air cooled, Argon-ion laser, 3-color system) to confirm the immunophenotype of the matured DC. Nonspecific PEconjugated antibody was used as a negative control. On day 7, irradiated tumor cells were combined with the DC at 3:1 (DC:tumor cells) ratio.

\section{Interferon gamma assay}

To assess the immune response, circulating serum interferon gamma was measured by ELISA kit (BD Biosciences) following the manufacturer's procedure. ${ }^{9}$ Approximately $4 \mathrm{~mL}$ whole blood was extracted at baseline and prior to each dose of DC. The interferon gamma was measured in triplicates. Due to sample constraints, the assay was performed once only.

\section{Sterility test and release criteria}

Following the standards set by the International Society of Stem Cell Research, ${ }^{10}$ a stringency test on sterility was carried out. Growth for bacteria was tested using thioglycolate broth and plated onto agar plates. The release criterion for DC was set at $80 \%$ cell viability.

\section{Administration of DC and Monitoring of Patient}

Approximately $6 \times 10^{6}$ matured and primed DC were injected intradermally on both locally anesthetized deltoid sides of the patient. Vitals were monitored three times for the first one hour, and periodically carried out for the duration of $24 \mathrm{~h}$. The first two injections were given two weeks apart and the succeeding DC administration was performed one month after the first dose.

\section{Discussion}

The pleomorphic lung carcinoma was grown in vitro (Figure 1). These cells can be a good source of tumor antigen for the patient. However, in cancer patients (in vivo), cytokines and other factors released by the tumor cells can lead to immune cell incompetence. In addition, a recent report suggests that cancer cells can induce apoptosis of DC. ${ }^{11,12}$ The challenge then, is to develop a system that will lead to the most favorable tumor antigen priming in cancer immunotherapy. Our study hinged upon culturing the DC ex vivo, in order to provide an optimal environment for the DC. Leukapheresis was carried out to obtain peripheral hematopoietic stem cells. CD34 expression was used as a surrogate marker to identify hematopoietic stem cells. Morphological changes were noted in the photomicrograph of the DC (Figure 2). Induction of DC maturation was confirmed using flow cytometry as shown in Figure 3. The percent of matured DC, which is CD86 positive, is $75.4 \%$. This is based on the rightward shift of the signal when compared against the negative PE-control. Matured DC were pulsed with irradiated autologous tumor cells. The pulsing was carried out for at least 15 hours at $37^{\circ} \mathrm{C}$ with 5 $\% \mathrm{CO}_{2}$. Rosette formation, which is a classic sign of immune activation in vitro, was noted when DC were cultured with the tumor cells (Figure 4). The illuminated cells are CD86 positive cells (Figure 4).The figure suggests that the DC were competent to recognize the tumor cells. Serum interferon gamma was measured as a surrogate marker for immunostimulation. As shown in Figure 5, a steady increase in the serum interferon gamma was observed during the course of DC administration over a period of two months. An approximately 5-fold increase in serum interferon gamma was detected after the third dose (or 4 weeks after the first dose). This report demonstrates the feasibility of harvesting DC using apheresis and transplanting them back into the same patient. No adverse events, such as anaphylactic shock, severe local reaction, seizure, or lymphadenitis were noted post DC administration. Notably, the pleomorphic lung cancer continued to progress despite DC transplantation. The increase in the serum interferon gamma did not correlate with the disease progression. By contrast, we have another study (manuscript in preparation) wherein three patients who showed an increase in interferon gamma also had no progression of the disease. With more subjects, DC therapy may offer a clinical benefit with virtually no adverse event. 


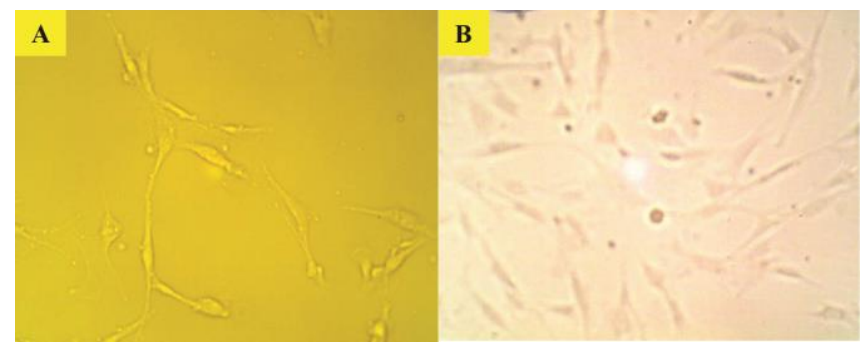

Figure 1. Photomicrograph of tumor cells grown in RPMI1640 with autologous serum plus antibiotics at 200x. Spindle-shape cells were grown from a lower confluency (A) about $15 \%$ to a confluency of $50 \%$ (B). These tumor cells were used to prime the DC.
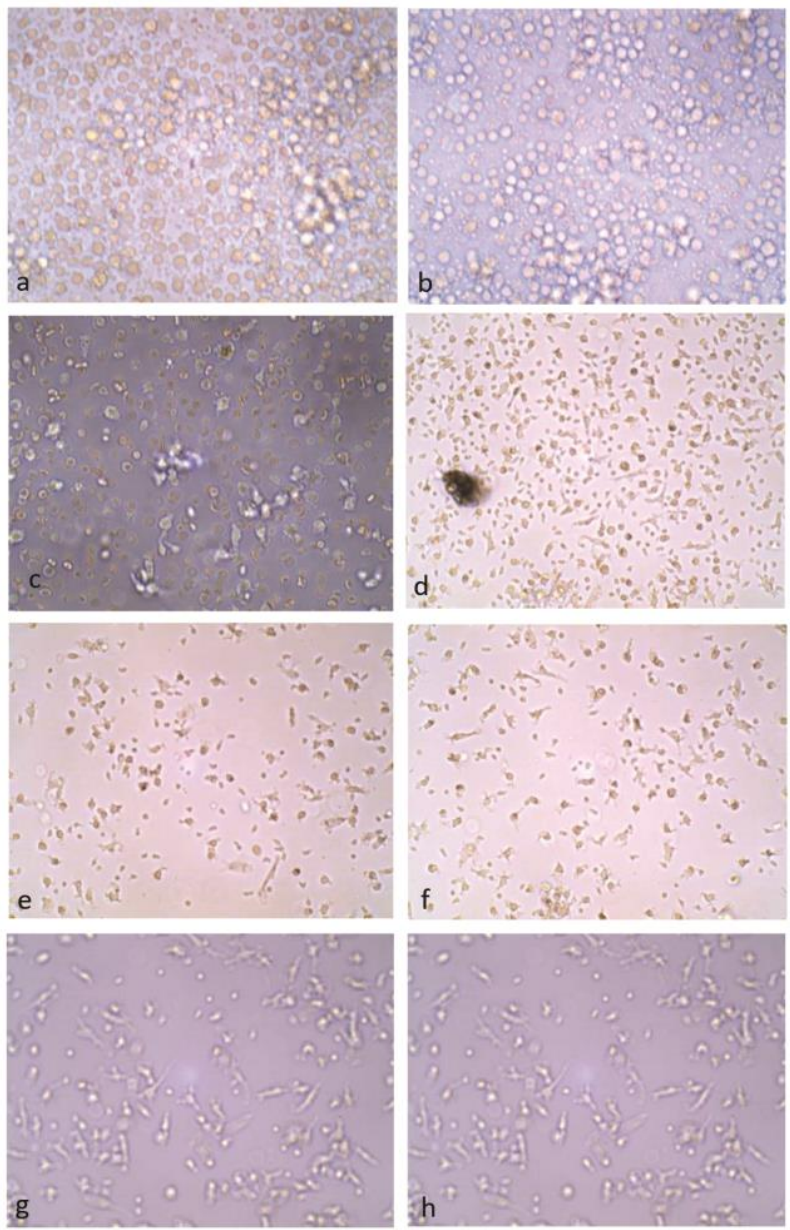

Figure 2. Photomicrograhs of DC shows the morphological changes over time (100 x). DC (a) at day 0, (b) at day 1, (c), at day $2,(\mathrm{~d})$ at day $3,(\mathrm{e})$ at day $4,(\mathrm{f})$ at day $5,(\mathrm{~g})$ at day $6,(\mathrm{~h})$ at day 7 The fingerlike structures started to appear on Day 3 and became more apparent on Day 4.
CD 86-PE (DAY 7) MATURED DC
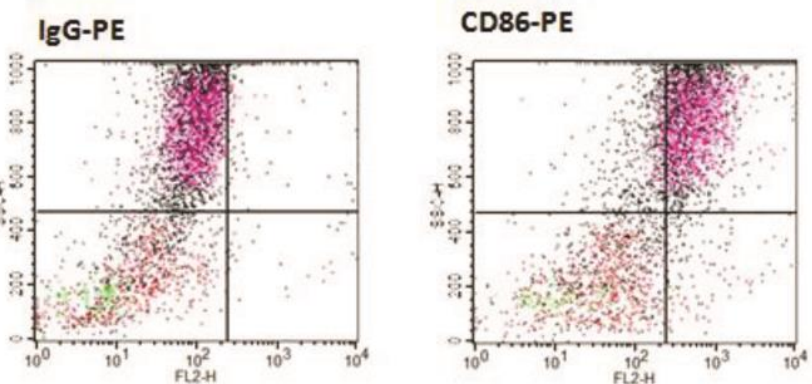

Figure 3. Flow cytometric analysis demonstrated rightward shift with CD-86-positive cells (right panel) PE-conjugated when compared with the nonspecific PE-conjugated antibody (left panel, negative control) on Day 7 DC. The background signal was shown in IgG-PE panel and the CD86 positive cells were measured. The PE fluorescence is read at FL2 channel (x-axis). The granularity of the DC is shown on the side-scatter channel (SSC,y-axis).

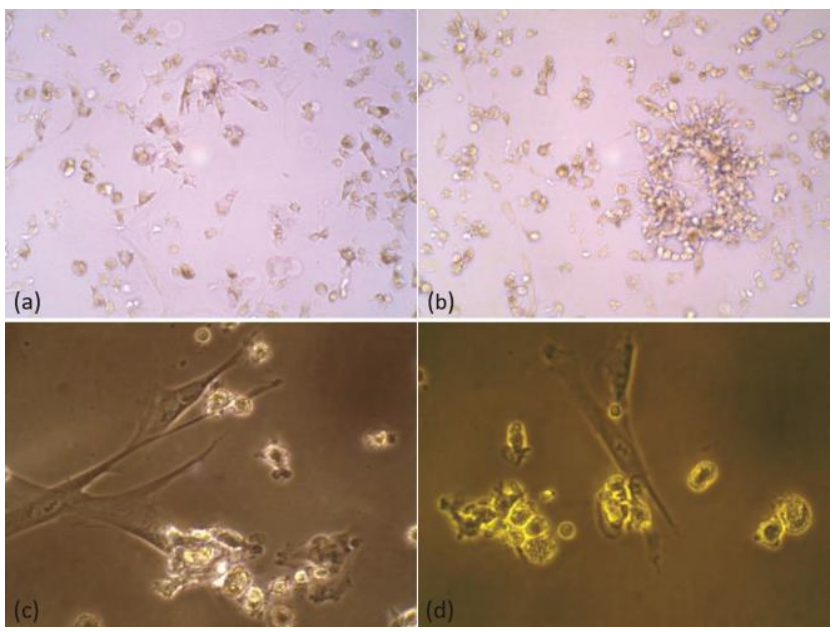

Figure 4. DC Priming. DC were cultured with the irradiated tumor cells. DC started to round up the tumor cells ( $\mathrm{a}$ and $\mathrm{b}$ at 200x). Surface marker for matured DC, CD-86, confirmed that the competent immune cells (illuminated DC) bind to the non-illuminated tumor cells (c and d at 400x) 


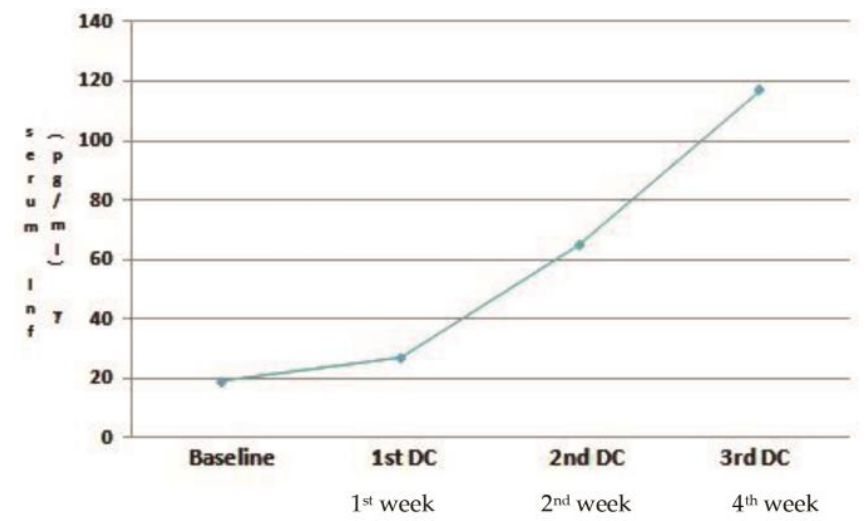

Figure 5. Serum Interferon gamma assay. Consistent increasing pattern in serum interferon gamma in $\mathrm{pg} / \mathrm{ml}$ production was noted during DC administration.

\section{Conclusion}

The study demonstrated the safety and feasibility of autologous DC transplantation. In addition, DC harvesting and induction of maturation was achieved. The administration of matured and primed DC resulted in increased levels of circulating interferon gamma. The increase in the magnitude of immune response, as shown by the interferon gamma was not able to prevent the progression of cancer in the patient. No adverse effect was noted when the DC were transplanted.

\section{References}

1. World Health Organization. Histological typing of lung tumors, $3^{\text {rd }}$ ed. Geneva: World Health Organization. 1999.

2. Kantoff PF, Higano CS, Shore ND, et al. Sipuleucel-T immunotherapy for castration-resistant prostate cancer. New Engl J Med. 2010; 363(5):411-22.

3. Provenge-FDA-approved [online]. [cited 2011 Jan]. Available from http://www.fda.gov/downloads/BiologicsBloodVaccines/CellularGeneT herapyProducts/ApprovedProducts/UCM210031.pdf

4. Hirschowiz E, Foody T, Kryscio K, Dickson L, Sturgill J, Yanelli J. Autologous dendritic cell vaccines for non-small-cell lung cancer. J Clin Oncol. 2004; 22(14): 2808-15.

5. Chiappori AA, Soliman H, Jansenn WE, Antonia SJ, Gabrilovich DI. INGN-225: a dendritic cell-based p53 vaccine (Ad.p53-DC) in small cell lung cancer: observed association between immune response and enhanced chemotherapy effect. Expert Opin Biol Ther. 2010; 10(6):98391.

6. Li H, Wang C, Yu J, et al. Dendritic cell activated cytokine-induced killer cells enhance the anti-tumor effect of chemotherapy on non-small cell lung cancer in patients after surgery. Cytotherapy. 2009; 11(8):1076-83.

7. Palucka K, Banchereau J. Cancer immunotherapy via dendritic cells. Nat Rev Cancer. 2012; 12(4):265-77.

8. World medical association declaration of Helsinki Ethical Principles for Medical Research Involving Human Subjects [online]. [cited 2012 Mar]. Available from http://www.who.int/bulletin/archives/79(4)373.pdf

9. Becton, Dickinson and Company. Human IFN- $\gamma$ ELISA Kit II Instruction Manual. 2007.

10. Guidelines for the Clinical Translation of Stem Cells [online]. 2008 [cited 2012 Mar]. Available from http://www.isscr.org/clinical_trans/ pdfs/ISSCRGLClinicalTrans.pdf.

11. Gabrilovich D. Mechanisms and functional significance of tumourinduced dendritic-cell defects. Nat Rev Immunol. 2004; 4(12):941-52.

12. Boissonnas A, Scholer-Dahirel A, Simon-Blancal V, et al. Foxp3+ T cells induce perforin-dependent dendritic cell death in tumor-draining lymph nodes. Immunity. 2010; 32(2):266-78.

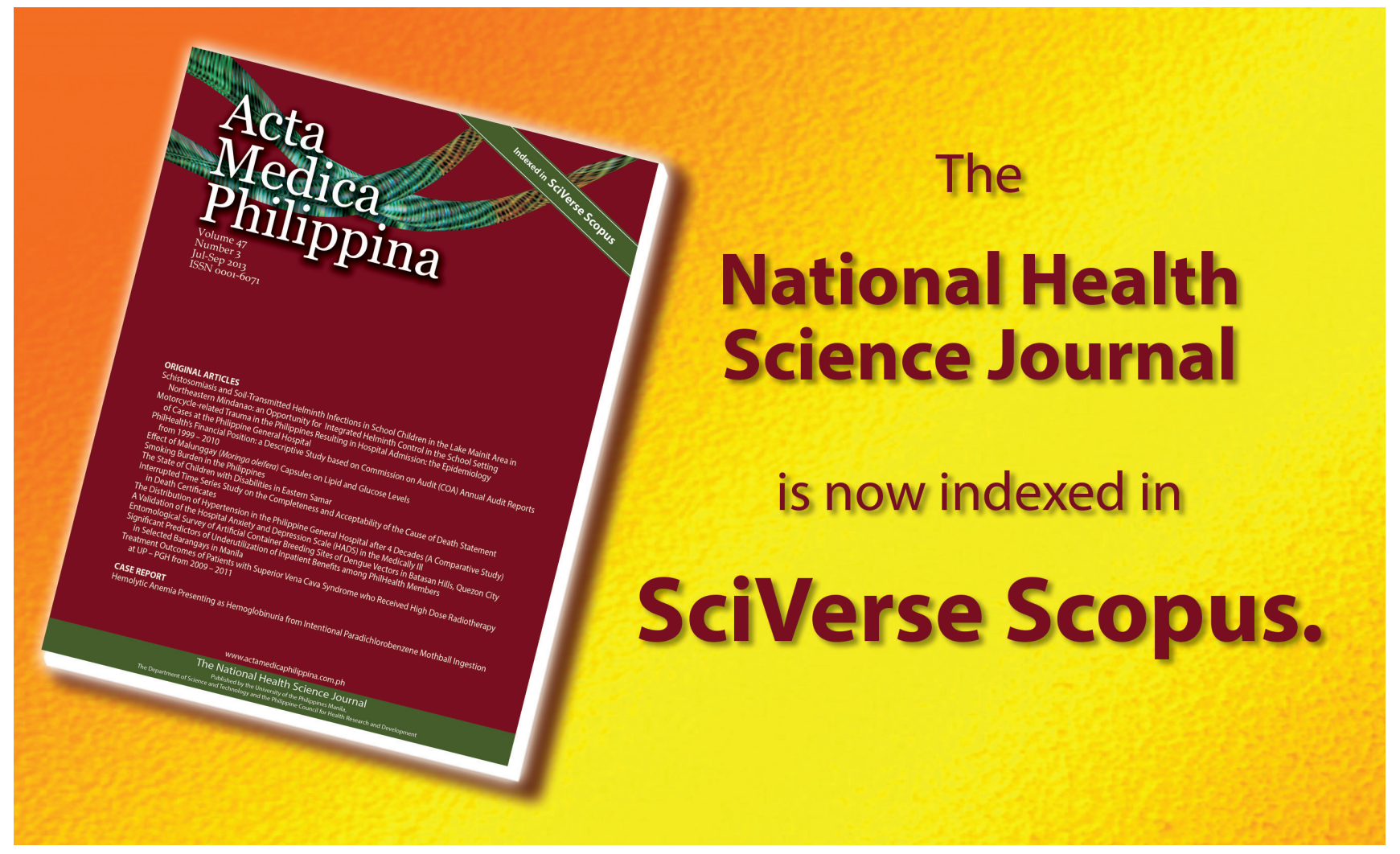

